\title{
The Role of Photoluminescent Pigments in Textiles
}

\author{
Richa Sharma ${ }^{1 *}$ and Nilanjana Bairagi ${ }^{2}$ \\ ${ }^{1}$ Department of Textile Design, National Institute of Fashion Technology, India \\ ${ }^{2}$ Department of Knitwear Design, National Institute of Fashion Technology, India \\ *Corresponding author: Richa Sharma, Department of Textile Design, National Institute of Fashion Technology, Bengaluru, India

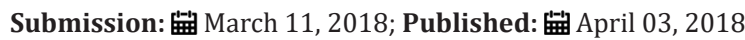

\begin{abstract}
Photoluminescent pigments are specialty pigments which possess a unique property of glow in the dark. In absence of any light source in dim and dark light conditions, photoluminescent pigments tend to emit light which opens up new areas of applications, especially in the field of textiles. This paper explores the concept of photoluminescence and factors affecting the performance. This paper also looks at the various applications that have emerged in the area of textiles while embarking on future scope of research and experimentation.
\end{abstract}

Keywords: Photoluminescent pigment, Textiles, Paints and coatings, Safety gear, Printing

\section{Introduction}

Photoluminescent pigments fall into the category of 'glow in the dark' specialty pigments. Specialty pigments are known for their unique properties and specialized application which in this case is of emission of light in absence of any light source i.e. in dim and dark lighting conditions. These advantages in the properties of photoluminescent pigments not only improve the aesthetic appeal of the textiles on application but also increase the functionality of the textiles. With the growing lifestyle and expendable income of the present day consumers the market is primed for growth in application as paints, coatings, prints, vinyl stickers and sometimes even in the dope of polymers. The varied mediums of application allow immeasurable capacity of growth of the photoluminescent pigments in the area of textile application. Rising demand from construction and automotive industries are also anticipated to drive the market growth. Therefore, the objective of this paper is to review the application areas of photoluminescent pigments in the field of textiles.

\section{Background}

There are several kinds of photoluminescent materials available commercially [1]. There are other sources of similar luminescence apart from photoluminescence pigments. Table 1 gives a brief overview of various sources for luminescence with corresponding application areas [2]. Luminescence is different from incandescence. Incandescence is the phenomena like a conventional light bulb where light is emitted by the heating of filament to cause luminescence. The light emission in the case of photoluminescence is a cold body radiation which may be seen due to chemical reactions, electrical energy, subatomic motions or stress on a crystal can cause luminescence. The luminescent pigments are capable of emitting photoluminescence.

Table 1: Types of luminescence and applications cited from [2].

\begin{tabular}{|c|c|c|}
\hline Luminescence & Energy Source & Typical Uses \\
\hline Cathodoluminescence & High energy electrons & Cathode ray tubes (CRTs) \\
\hline Photoluminescence & High energy & UV Fluorescent lighting, plasma display panels \\
\hline Phosphorescence & Photons (UV or visible) & Pigments, safety signs, low energy lighting, analysis \\
\hline Fluorescence Photons & (UV, visible or near-IR) & $\begin{array}{l}\text { Pigments, inks, optical brighteners, safety signs and clothing, analysis, } \\
\text { biology, molecular electronics }\end{array}$ \\
\hline Chemiluminescence & Chemical reactions & Analysis, sensors, \\
\hline Bioluminescence & Various luminous organisms & Analysis, diagnostics, sensors \\
\hline Electroluminescence & Electric field & LEDs, displays, back lighting, opto-electronics \\
\hline Triboluminescence & Mechanical shaking, rubbing or crushing & Crack detection in composite materials \\
\hline
\end{tabular}




\section{Fluorescence and Phosphorescence}

Glow in the Dark pigments comprises of both usually fluorescent dye and the phosphorescent compound. The phosphorescent material absorbs light and emits it slowly as a pale blue light. Then the pale blue light is absorbed by the fluorescent dye and emitted as a green or red light depending on the dye used. The most commonly used phosphorescent material is zinc sulfide mixed with copper. The green fluorescent dye is mostly sodium fluoresce in and the red fluorescent dye is a Rhoda mine. Since fluorescence is a much faster process than phosphorescence, the phosphorescent material forms the source and the fluorescence material takes up the role of the device for energy consumption.

The name fluorescence is derived from the fluorescent mineral Fluorite (fluorspar, Calcium-fluoride, CaF2). The first synthetic, phosphorescent material that is known was the Lapis Solaris, which is also known as the luminous stone of Bologna. The famous shoemaker and alchemist Vicento Cascariolo in Bologna, Italy produced this material in 1604. Phosphorescence is the appearance of afterglow, it is a property possessed in particular by phosphorus (light carrier) [3].

\section{Principle of Phosphorescence}

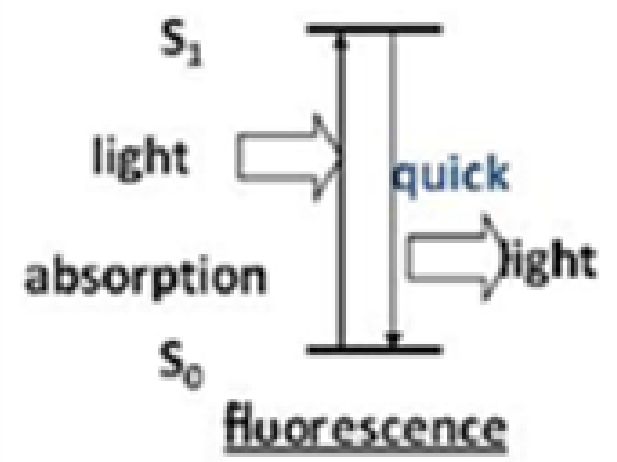

Figure 1: Principle of phosphorescent material.

Phosphorescence phenomenon is based on a physical effect, which is actually the retransmission of light energy accumulated previously during illumination. Compared with fluorescence phenomenon, the process of phosphorescence is slower, as cited by Wang et al. [1] and as shown Figure 1.

\section{Measurement of Photoluminescence (PL)}

Photoluminescence (PL) in terms of intensity and decay can be measured to characterize a variety of material parameters. PL spectroscopy provides electrical (as opposed to mechanical) characterization, and it is a selective and extremely sensitive probe of discrete electronic states. Time resolved spectroscopy provides fast and useful measure for PL [4].

PL is affected by surfaces and interfaces. Smooth and atomically abrupt interfaces are necessary for good optical and electrical reflection, uniform quantum confinement, and high carrier mobility. Even more importantly, defects and impurities at interfaces provide new states for electrons and holes, altering their motion, lifetime, and transition energies [5].

PL also depends on the nature of the optical excitation. The PL signal often depends on the density of photo-excited electrons, and the intensity of the incident beam can be adjusted to control this parameter. PL is generally not sensitive to the pressure in the sample chamber. In addition, PL has little effect on the surface under investigation.

\section{Applications of Photoluminescent Pigments}

Traditionally, the most popular uses of PL is seen in clock, watch and instrument dials, which are required to be visible in temporary, poor lighting conditions. They are also widely used in novelty items such as plastic toys and in sporting goods, for example as fish floats. Phosphorescent pigments are also used in security applications, such as the coding of bank cheques, cards, passports and tickets and on bank notes often in conjunction with machine-readable information. Along established, non-security application for such materials has been in postal envelope sorting.

The availability of commercial quantities of doped alkaline earth aluminates (AEAs) in the mid-1990s extended the scope and uses of phosphorescent pigments. AEAs are commonly based on strontium aluminate, which provide a remarkably long afterglow of over $12 \mathrm{~h}$, coupled with high stability. The alkaline earth aluminates are available for formulation into paints and coatings, UV cured and silk screen inks.

With these reasonably recent developments, phosphorescent pigments are being used safely in a wide variety of applications which include: consumer products, such as clothing, shoes, caps, 
toys, stationery goods, and watches, novelties, fishing tools and sporting goods. Phosphorescent materials are known in the field ink, paint and tapes; and they are also used on clocks, light switches, some stickers, fishing net, artificial baits, etc. Fluorescent materials are mostly used in textile-applications like filaments, coatings or signalization [6].

\section{Application of Photoluminescent Pigments as Tapes and Yarns}

Various companies like 3M , Lightleader Co. Ltd., Luminochem Industries etc. have commercial products such as "Safety-Walk MR Clear Phosphorescent" tapes, phosphorescent pigments for coating and phosphorescent yarns [7], Lumi Nova®, Luming ${ }^{\circledR}$ photo luminescent pigments, etc. which are widely used for markers and signage. The pigment is widely used in the fields of consumer goods, decorations, communication and transportation, military facilities, and fire emergency system etc.

Ocean and Sea, is a conceptual solution for knitted textile dividers. During the day and night, with the use of photoluminescent yarns used in the sea layered with ocean which is photo chromatic creates a healing environment in the hospitals [8].

\section{Application of Photoluminescent Pigments as Textile Pigments \& Coatings}

As PL pigment is non-radioactive, non-toxic and can be mixed as additive with the transparent media as printing ink, paint, plastics, printing paste, ceramics, glassware and yarn to enable the media to glow in the dark [1,9-12]. These pigments can glow different colors in the dark, and works with good performance for low-location emergency lighting, indication marks and decorations. Though these products were originally developed to satisfy the current and future needs of the clock, watch and the instrument dial industries but today it commands many applications in new applications especially in textiles.

\section{Photo-luminescent pigments application on textiles as coatings and laminates}

As laminates photoluminescent pigments exhibits outstanding after-glow properties and pleasing appearance to the eye even after been exposed to extreme conditions of use $[13,14]$. These sheet materials comprise a textile sheet material substrate, a coating layer consisting of one or more synthetic resins admixed with a photo luminescent complex. The sheet materials may be textile sheet materials useful for the production of garments, in particular safety garments and furnishing fabrics. Self-adhesive materials may also be produced with PL pigments.

\section{Photo-luminescent pigments application on textiles as dyes \& paints}

Photoluminescent compositions with dyes or paints give the opportunity to the user to add colorant to the articles that are luminescent in the dark and that have a good appearance at a relatively low cost. A further object is to provide paints and dyes, in particular for spray coating, that can be used in the interior as well as in the outdoor area, that adhere to materials, such as textile, metal, stone, glass, plastics, concrete, wood and asphalt with the help of a suitable binder [15]. There is limited literature on the application of photoluminescent pigments as prints on textiles.

\section{Photo-luminescent pigments application on textiles in fiber stage}

Photo-luminescent Pigments can also be used on textiles in fiber stage or dope for providing uminescence to fibrous material [1618]. The method includes incorporating a metal aluminate oxide pigment with a thermoplastic polymer, and then heating, thorough mixing, and extruding the combination into a filament. This gives an avenue to mould this into inventive fibers, fabrics made thereafter, and objects containing the fiber. The photo-luminescent fibers can thus be charged with naturally occurring illumination. The fastness properties of these filaments and fibres are generally good as they are trapped within the fibre structure and do not get washed off during laundering of the textiles.

\section{Photo-luminescent pigments application on textiles as safety gear}

Photo-luminescent products such as sheeting and tapes are used extensively as application on textiles as safety gear and guiding systems for emergency exits and escape routes; also used for hazard notifications and safety devices. These new materials have great potential in supporting the safe evacuation of building occupants for use as a safety way-guidance system. 'Self-Illuminated Safety Jackets' have created a product, which involved the optimum use of pigment concentration for various work wear safety gear in dark [19-22].

\section{Photo-luminescent pigments application on textiles for aesthetics}

Designers have worked in the area of high-tech fabrics, adopting electronic display technologies to create colorful, novelty clothing items [23-25]. Advances in textile technology, computer engineering and materials science have been promoting a new breed of functional fabrics. But very little experimentation has been made by designers in the area of photoluminescent pigments. There is limited study on designing a two-phase glow-in-thedark pattern on textiles to study the aesthetic potential of the PL pigments. Very basic vinyl stickers have been used for T-shirts and sometimes in sport shoes. With limited experimental research on of PL pigments especially in the area of printed textiles, constrains designers to work in areas of novel applications.

\section{Summary}

The paper reviews the various application areas that have emerged in the application of photoluminescent pigments. Mostly PL pigments have found application in paints, coatings, laminates, being incorporated in the polymer dope of man-made filaments and fibers, etc. The main focus of these applications has been on the functionality of these pigments like safety and way-finding. There is a huge potential for application of these pigments in the area of design and aesthetics of textiles for ambient lighting without the 
use of additional electrical power in nighttime environments [26]. There is limited research of these pigments in the application as textile prints which may be a gateway for designers to use these novel luminescent pigments as part of their surface ornamentation and design.

"The way to learn about new materials is through the material itself, to forget conventions and suggest new styles and semantics, starting with basic expressional experiments" [27].

Therefore, there is a need to study the applications of photoluminescent pigments in textile print paste with respect certain parameters like: concentration of the pigment in the print paste, particle size and type of PL pigments and correlate the photo luminescence emitted by different concentration and particle size of these pigments when applied through printing. Additionally, a detailed study on the luminosity of these pigments in a real night time environment is also necessary. These studies also need to be correlated with user studies in a real nighttime environment so that the application of these specialty pigments is based on empirical data. This would provide textile technologists and designers new avenues of applications in aesthetics designing of textile products, which are user-centric.

\section{References}

1. Wang S, Schwaiger NE (2010) Study in the field of product development about Illuminating material for fire-fighter garments \& others in the future. Master thesis, Boras, Europe.

2. Bamfield P (2010) Chromic Phenomena. The Royal Society of Chemistry.

3. Rouette HK (2001) Encyclopedia of Textile finishing. Springer pp. 1576.

4. Vikova M (2011) Photo chromic textiles. ROS Theses Repository, pp. 1-204.

5. Gfroerer TH (2000) Photoluminescence in Analysis of Surfaces and Interfaces. Encycl Anal Chem, pp. 9209-92031.

6. Thomas EMII (1988) Color compositions and method. Google Patents.

7. Glow yarns for special effects in fabrics. SWICO FIl.

8. (2009) Special edition. Nord Text Journal, pp. 1-106.
9. News L (2014) Photoluminescent Pigments \& Inks. LTI.

10. Luminochem (2015) Photoluminescent pigments.

11. Luminova (2009) Light fast-super bright long afterglow phosphorescent pigments afterglow. p. 1-8.

12. Kaya S, Karasu B, Karacaoglu E (2009) General review of application of phosphorescence pigments in ceramic industry. Seres, pp. 608-616.

13. Joseph G (1966) Phosphorescent coated textile. Google Patents, pp. 1922.

14. Gravisse PE, Van Schoote JF (1980) Photoluminescent textile materials. Google Patents.

15. Friedrich D (2013) Phosphorescent compositions and use thereof. Google Patents.

16. Geisel RH (1997) Method of providing luminescence to fibrous materials. Google Patents.

17. Bortz TE, Agrawal S, Shelnut JG (2012) Photoluminescent fibers, compositions and fabrics made there from. Google Patents.

18. Yanhong Yan, Yanan Zhu XG, MG (2014) The effects of inorganic pigments on the luminescent properties of colored luminous fiber. Text Res J 84(8): 785-792.

19.Zampa DE, Szopinski AA (1995) Photoluminescent retro-reflective sheeting. Google Patents.

20. Tonikian R, Proulx G, Bénichou N, Reid I (2006) Literature review on photoluminescent material used as a safety wayguidance system. Natl Res Counc Canada, pp. 1-31.

21. List L (2000) Pigments help light the way to escape. Financ Times Ltd, London, UK, pp. 8-10.

22. Gulrajani BML, Agarwal A, Bajaj A, Gupta A, Lohia C, Goel D (2008) Selfilluminated safety jackets. Asian Dye.

23. (2015) Nike Glow in the dark shoe.

24. Gould P (2003) Textiles gain intelligence. Mater Today 6: 38-43.

25. Kooroshnia M (2014) Designing a two phase glow in the dark pattern on textiles. Shape shifting A Conf Transform Paradig Fash Text Des pp. 1-16.

26. Lam F (2015) Rethinking the Shades of Night.

27. Worbin L (2010) Designing Dynamic Textile. Chalmers University of Technology, Gothenburg, Sweden.
Creative Commons Attribution 4.0

International License

For possible submissions Click Here

\section{Submit Article}

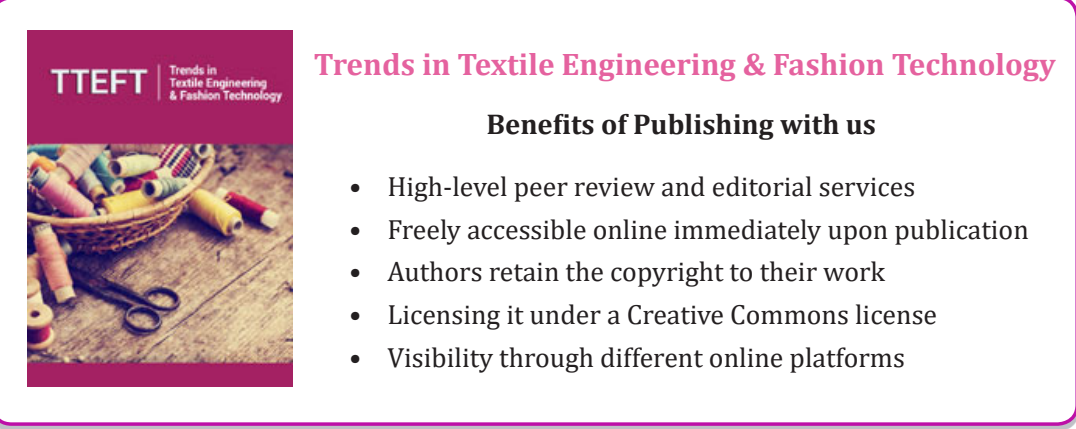

